\title{
A coupled elastoplastic damage model for brittle rocks
}

\author{
Zheng Li, Yundong Shou* \\ School of Civil Engineering, Wuban University, China \\ lizheng872@163.com, https://orcid.org/0000-0003-0321-0567 \\ shouyundong@wbu.edu.cn,https://orcid.org/0000-0001-7424-4006 \\ Deping Guo \\ Xuzhen Railway Co.,Ltd. Zhaotong 657900, Yunnan, China \\ guodeping99@qq.com
}

Filippo Berto

Norwegian University of Science and Technology, Norway

filippo.berto@ntnu.no

\begin{abstract}
Brittle rock contains an important plastic deformation, which causes microcracks when coupled with stress-induced damage. A new coupled elastoplastic damage model is established in order to discuss the damage behaviors found in brittle rock, based on theoretical analysis and experiments. Micromechanic considerations determine the effective elastic properties of anisotropic damaged geomaterials. An energy-based damage criterion is used to deduce the damage initiation and the damage evolution law of the brittle rocks. Moreover, the non-linear unified strength criterion is modified. It takes anisotropic damage and the effects of intermediate principal stress into account, in order to determine both the yield and plastic potential functions. The non-associated plastic flow rule is utilized. The consistency condition of plastic and damage is applied in the coupled process. The damage evolution rule and the coupled plastic damage of brittle rock are conceived within the framework of irreversible thermodynamics. By comparing the simulations and the experimental data from limestone that was subjected to various loading paths, a strong connection between the numerical simulations and experimental data is therefore obtained. The numerical results show that the new model is able to describe the main features of the mechanical properties observed in brittle rock.
\end{abstract}

KEYWORDS. Coupled elastoplastic damage model; Non-associated plastic flow rule; Anisotropic damage behaviors; Brittle Rock.

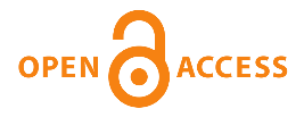

Citation: Li, Z., Shou, Y.D., Guo, D.P., Berto, F., A coupled elastoplastic damage model for brittle rocks, Frattura ed Integrità Strutturale, 53 (2020) 446-456.

Received: 23.4.2020

Accepted: 05.06 .2020

Published: 01.07.2020

Copyright: (C) 2020 This is an open access article under the terms of the CC-BY 4.0, which permits unrestricted use, distribution, and reproduction in any medium, provided the original author and source are credited. 


\section{INTRODUCTION}

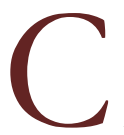

hina is one of the few countries in the world that use coal as an important power source. More than $70 \%$ of its total power generation is thermal power [1]. Its output has exceeded one third of the world's total output. The coal industry has played an important role in promoting national economic development, rapid economic growth and social progress. However, with the vigorous development of the coal industry, coal mine accidents have become a major obstacle to its development. Coal mine accidents are mainly included in the fields of gas burst, roof fall, rock burst and so on. Roof fall, as shown in Fig 1, is the most ordinary accident in coal mine. The number of roof fall accidents is accounting for $43 \%$ in coal mining accidents. Coal is a complex fractured geological medium containing numerous randomly distributed micro holes and cracks. Its mechanical properties are important essential parameters for the mining design, roadway support and some other underground coal engineering [2-4]. Therefore, the constitutive relation and damage model of coal-rock is still a major issue to be solved urgently.

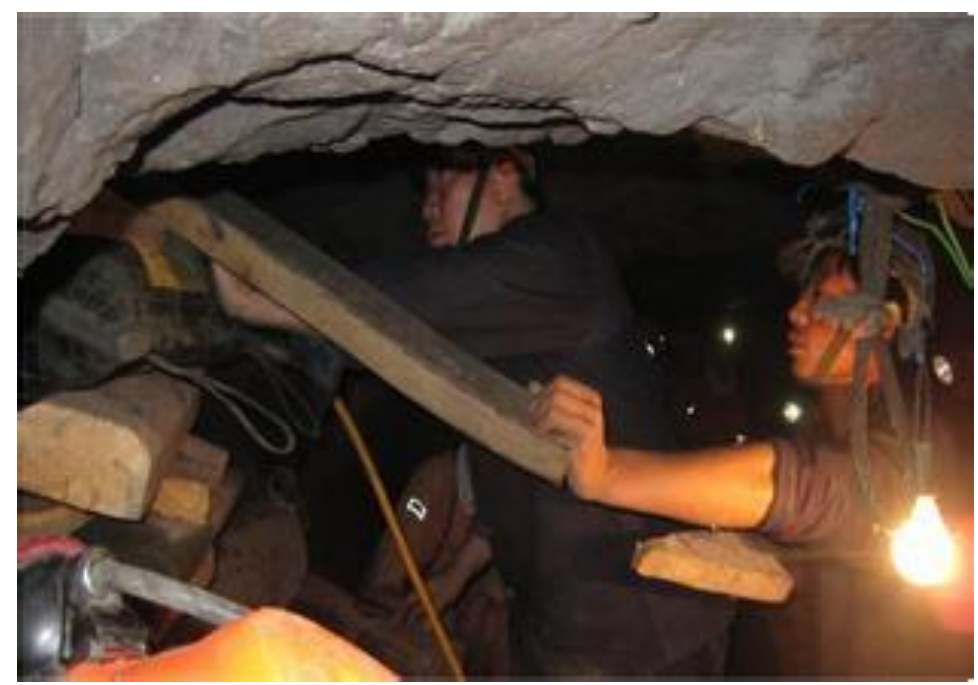

Figure 1: A roof fall accident happened in coal mine.

For the mechanical properties of coal-rock, the plastic/elastoplastic and damage model were the focus issues in the previous researches. Chen et al.[5] established a new permeability model considering plastic and failure behavior for coal, and discovered that the mechanical state (or deformation stage) of coal had a significant effect on permeability. Wu et al. [6] developed a plastic strain-based damage model that consists of the heterogeneity function, the damage stress-strain function, the cohesion function and the dilation angle function based on analysing the characteristics of coal dilation and strain hardening/softening during deformation. Zhou et al. [7] proposed a nonlinear constitutive equation of rocks by taking the nonlinear deformation properties of rocks into consideration. Moreover, both the nonlinear damage evolution equation and constitutive equation of rocks were deduced by applying the thermodynamics conservation laws [7]. Rock belongs to a typical heterogeneous material with very low tensile strength. The effects of temperature gradient on the damage of rocks were investigated by Zhou et al. [8] and Zuo et al. [9]. Li et al. [10] proposed a theoretical evaluation model of rock brittleness based on the statistical damage theory and the energy evolution law of rock failure process. In this model, the damage evolution of coal in loading process was considered.

The micromechanical damage mechanics approach leads to an improved understanding of the underlying physical processes [7,11-12]. In the micromechanical approach, researchers study the growth, nucleation, and coalescence of microcracks and their influence on the mechanical properties, which is reflected in the constitutive relation in certain ways [11-19]. Among these, the most widely used models are the dilute-concentration method (DCM), the self-consistent method [20-22], the differential method (DM) [23-24], the generalized self-consistent method (GSCM) [25], and finally, the effective selfconsistent method [26]. However, the micromechanical damage mechanics model is often difficult to implement in engineering applications, because of its proclivity to cause 3D problems. Therefore, the phenomenological approach is adapted in the new model. This article proposes a coupled elastoplastic damage model in order to discuss the plastic deformation and induced damage found in brittle geomaterials. Furthermore, the new coupled model describes the anisotropic damage behaviors of geomaterials in triaxial and uniaxial compressive tests. 


\section{GENERAL IDEA FOR THE COUPLED ELASTOPLASTIC DAMAGE MODEL}

$\mathrm{B}$ ased on our theoretical analysis and experimental investigations, a coupled elastoplastic damage model is established to describe the mechanical behaviors of semi-brittle geomaterials. As mentioned earlier, an anisotropic damage model can be used to describe the degradation process that is induced by the microcracks found in semi-brittle geomaterials. Generally, small strain assumption is adopted, and the total strain tensor can be decomposed into an elastic part, $\boldsymbol{\varepsilon}^{e}$ and a plastic part, $\boldsymbol{\varepsilon}^{p}[7,12,27-28]$

$$
\dot{\boldsymbol{\varepsilon}}=\dot{\boldsymbol{\varepsilon}}^{e}+\dot{\boldsymbol{\varepsilon}}^{p}
$$

In an isothermal process without viscous dissipation, Helmholtz free energy is dependent on three state variables:

$$
\psi=\psi\left(\boldsymbol{\varepsilon}^{e}, \gamma_{p}, \boldsymbol{D}\right)
$$

where $\boldsymbol{\varepsilon}$ denotes the elastic strain tensor, $\gamma_{p}$ represents the scalar-valued internal variables of plasticity, and D refers to the tensor-valued internal variables of damage.

Assuming that a thermodynamic potential exists in the damaged elastoplastic geomaterials, plastic deformation and plastic hardening both occur within the damage process. Helmholtz free energy can be resolved into elastic and plastic components:

$$
\psi=\psi\left(\boldsymbol{\varepsilon}, \gamma_{p}, \boldsymbol{D}\right)=\psi^{e}(\boldsymbol{\varepsilon}, \boldsymbol{D})+\psi^{p}\left(\gamma_{p}, \boldsymbol{D}\right)
$$

where $\psi^{p}\left(\gamma_{p}, \boldsymbol{D}\right)=(1-\mu t r \boldsymbol{D}) \psi_{p}^{0}\left(\gamma_{p}\right), \psi_{p}^{0}\left(\gamma_{p}\right)=\left(\alpha_{p}^{m}-\alpha_{p}^{0}\right)+\left(\alpha_{p}^{m}-\alpha_{p}^{0}\right) \gamma_{p}+B\left(\alpha_{p}^{m}-\alpha_{p}^{0}\right) \gamma_{p}^{2}, \alpha_{p}^{0}$ is the initial plastic yielding threshold, $\alpha_{p}^{m}$ is the ultimate value of hardening function, $B$ is a model's parameter controlling plastic hardening rate, and $\mu$ is the model's parameter coupling of damage evolution and plastic flow.

To insure that the second law of thermodynamics is justified, the Clausius-Duhem's inequality principle indicates that the reduced dissipation inequality contains:

$$
\boldsymbol{\sigma}: \dot{\varepsilon}-\dot{\psi} \geq 0
$$

The evaluation of the inequality involves the time derivative of the Helmholtz free energy:

$$
\dot{\psi}\left(\boldsymbol{\varepsilon}, \gamma_{p}, \boldsymbol{D}\right)=\frac{\partial \psi^{e}}{\partial \boldsymbol{\varepsilon}}: \boldsymbol{\varepsilon}+\frac{\partial \psi^{e}}{\partial \boldsymbol{D}}: \dot{\boldsymbol{D}}+\frac{\partial \psi^{P}}{\partial \gamma_{p}} \dot{\gamma}_{p}+\frac{\partial \psi^{p}}{\partial \boldsymbol{D}}: \dot{\boldsymbol{D}}
$$

Substitution in the reduced dissipation inequality results in:

$$
\left(\boldsymbol{\sigma}-\frac{\partial \psi^{e}}{\partial \boldsymbol{\varepsilon}^{\boldsymbol{e}}}\right): \dot{\boldsymbol{\varepsilon}}+\frac{\partial \psi^{e}}{\partial \boldsymbol{\varepsilon}^{\boldsymbol{e}}}: \dot{\boldsymbol{\varepsilon}}^{p}-\frac{\partial \psi^{e}}{\partial \boldsymbol{D}}: \dot{\boldsymbol{D}}-\frac{\partial \psi^{P}}{\partial \gamma_{p}} \dot{\gamma}_{p}-\frac{\partial \psi^{p}}{\partial \boldsymbol{D}}: \dot{\boldsymbol{D}} \geq 0
$$

where the additive decomposition is utilized in consideration of the elastic and plastic strain contributions. The thermodynamic conjugate forces for plasticity and damage are, respectively:

$$
\begin{aligned}
& R_{p}=-\frac{\partial \psi^{P}}{\partial \gamma_{p}} \\
& \boldsymbol{Y}=-\frac{\partial \psi}{\partial \boldsymbol{D}}
\end{aligned}
$$


Non-linear poroelastic behavior

Consider a geomaterial sample with the size $V$ weakened by microcracks. It is assumed that the damage tensor is just the second-order fabric tensor. Then, the damage tensor can be defined as [29]

$$
\boldsymbol{D}=\frac{1}{V} \sum_{\alpha=1}^{N} r_{\alpha}^{3} \boldsymbol{n}^{\alpha} \boldsymbol{n}^{\alpha}
$$

where $r_{\alpha}$ and $\boldsymbol{n}^{\alpha}$ are the radius and normal vector of the $a$ - crack.

If the crack density is small, interaction among cracks can be neglected. The Helmholtz free energy function can be expressed as follows [30-31]:

$$
\begin{aligned}
\psi^{e}\left(\boldsymbol{\varepsilon}^{e}, \boldsymbol{D}\right) & =\frac{E_{0}}{2\left(1+v_{0}\right)}\left[\frac{v_{0}}{1-2 v_{0}}\left(\operatorname{tr} \boldsymbol{\varepsilon}^{e}\right)^{2}+\operatorname{tr}\left(\boldsymbol{\varepsilon}^{e} \cdot \boldsymbol{\varepsilon}^{e}\right)\right]+b_{1} \operatorname{tr} \boldsymbol{D}\left(\operatorname{tr} \boldsymbol{\varepsilon}^{e}\right)^{2} \\
& +b_{2} \operatorname{tr}\left(\boldsymbol{\varepsilon}^{e} \cdot \boldsymbol{\varepsilon}^{e} \cdot \boldsymbol{D}\right)+b_{3} \operatorname{tr} \boldsymbol{\varepsilon}^{e} \operatorname{tr}\left(\boldsymbol{\varepsilon}^{e} \cdot \boldsymbol{D}\right)+b_{4} \operatorname{tr} \boldsymbol{D} \operatorname{tr}\left(\boldsymbol{\varepsilon}^{e} \cdot \boldsymbol{\varepsilon}^{e}\right)
\end{aligned}
$$

where $E_{0}$ is Young's modulus, $v_{0}$ is Poisson's ratio,

$$
\begin{aligned}
& b_{1}=-\frac{E_{0}^{2}}{\left(1+v_{0}\right)^{2}\left(1-2 v_{0}\right)^{2}}\left[a_{1}\left(1+v_{0}\right)^{2}+a_{2} v_{0}^{2}+a_{3} v_{0}\left(1+v_{0}\right)+a_{4}\left(2 v_{0}-v_{0}^{2}\right)\right], b_{2}=-\frac{a_{2} E_{0}^{2}}{\left(1+v_{0}\right)^{2}}, \grave{u} \\
& b_{3}=-\frac{E_{0}^{2}}{\left(1+v_{0}\right)^{2}\left(1-2 v_{0}\right)}\left[2 a_{2} v_{0}+a_{3}\left(1+v_{0}\right)\right], b_{4}=-\frac{a_{4} E_{0}^{2}}{\left(1+v_{0}\right)^{2}}, a_{1}=-\frac{c}{70} h, a_{2}=\frac{7+2 c}{7} h, a_{3}=\frac{c}{7} h, a_{4}=-\frac{c}{35} h, \\
& b=\frac{16\left(1-v_{0}^{2}\right)}{3 E_{0}\left(2-v_{0}\right)}, c=-v_{0} \text { (when cracks are open), } c=-2 \text { (when cracks are closed). }
\end{aligned}
$$

The standard derivation of the thermodynamic potential satisfies the state equation:

$$
\boldsymbol{\sigma}=\frac{\partial \psi^{e}\left(\boldsymbol{\varepsilon}^{e}, \boldsymbol{D}\right)}{\partial \boldsymbol{\varepsilon}^{e}}=\boldsymbol{E}(\boldsymbol{D}): \boldsymbol{\varepsilon}^{e}
$$

where

$$
\begin{aligned}
E_{i j k l}(D) & =\frac{E_{0} v_{0}}{\left(1+v_{0}\right)\left(1-2 v_{0}\right)} \delta_{i j} \delta_{k l}+\frac{E_{0}}{2\left(1+v_{0}\right)}\left(\delta_{i k} \delta_{j l}+\delta_{i l} \delta_{j k}\right) \\
& +2 b_{1}(t r D) \delta_{i j} \delta_{k l}+\frac{1}{2} b_{2}\left(\delta_{i k} D_{j l}+\delta_{i l} D_{j k}+D_{i k} \delta_{j l}+\delta_{i l} D_{j k}\right) \\
& +b_{3}\left(\delta_{i j} D_{k l}+D_{i j} \delta_{k l}\right)+b_{4}(t r D)\left(\delta_{i k} \delta_{j l}+\delta_{i l} \delta_{j k}\right)
\end{aligned}
$$

Eqn. (9) and Eqn. (11) describe the initial anisotropic elastic damage behaviors of geomaterials.

\section{Damage Characterization}

Damage kinetics may be determined by the pseudo-potential of dissipation. The damage initiation and the damage evolution law are controlled by the damage's energy release. The damage initiation and the damage evolution law are concluded in the case of non-viscous dissipation using a damage criterion, which is a scalar-valued function of damage energy release. The energy-based damage criterion is contemplated in the following form [32-33]: 


$$
F^{D}(\boldsymbol{Y}, \boldsymbol{D})=Y_{D}-R(\boldsymbol{D})=Y_{D}-\left[Y_{0}+k(\operatorname{tr} \boldsymbol{D})\right] \leq 0
$$

where $Y_{D}=[\operatorname{tr}(\boldsymbol{Y} \cdot \boldsymbol{Y})]^{1 / 2}, Y_{0}$ represents the damage energy release threshold at a given value of damage, and $k$ is the parameter controlling the damage evolution rate.

A normal dissipation scheme is utilized to obtain the damage evolution rate. The damage evolution rate is expressed as follows:

$$
\dot{\boldsymbol{D}}=\dot{\lambda}^{D} \frac{\partial F^{D}(\boldsymbol{Y}, \boldsymbol{D})}{\partial \boldsymbol{Y}}
$$

in which the damage multiplier $\dot{\lambda}^{D}$ is a positive scalar originated from the loading-unloading conditions.

The Kuhn-Tucker relations can be written as:

$$
F^{D}(\boldsymbol{Y}, \boldsymbol{D})=0, \dot{\lambda}^{D} \geq 0, \quad \dot{\lambda}^{D} F^{D}(\boldsymbol{Y}, \boldsymbol{D})=0
$$

Specifically, in the case of elastic damage loading without plastic flow $\left(\dot{\varepsilon}^{p}=0\right)$, the damage consistency condition is expressed by: $\dot{F}^{D}(\boldsymbol{Y}, \boldsymbol{D})=\frac{\partial F^{D}}{\partial \boldsymbol{Y}}: \dot{\boldsymbol{Y}}+\frac{\partial F^{D}}{\partial \boldsymbol{D}}: \dot{\boldsymbol{D}}=0$, and Eqn. (13) gives the rate of the damage multiplier:

$$
\dot{\lambda}^{D}=\frac{\partial \mathbf{Y}}{\partial \varepsilon^{e}}: \dot{\varepsilon} \frac{1}{R^{\prime}(\boldsymbol{D})}=-\frac{\left(\mathbf{E}^{\prime}(\boldsymbol{D}): \varepsilon^{e}\right): \dot{\varepsilon}}{R^{\prime}(\boldsymbol{D})}
$$

where

$$
\boldsymbol{E}^{\prime}(\boldsymbol{D})=\frac{\partial \boldsymbol{E}(\boldsymbol{D})}{\partial \boldsymbol{D}}, R^{\prime}(\boldsymbol{D})=\frac{\partial \mathrm{R}(\boldsymbol{D})}{\partial \boldsymbol{D}}
$$

Therefore, the rate form of constitutive equation turns into:

$$
\dot{\sigma}=\mathbf{E}^{\text {ed }}(\boldsymbol{D}): \dot{\varepsilon}
$$

where $\mathbf{E}^{\text {ed }}(\boldsymbol{D})$ is the tangent elastic damage tensor:

$$
\mathbf{E}^{e d}(\boldsymbol{D})=\mathbf{E}(\boldsymbol{D})-\frac{1}{R^{\prime}(\boldsymbol{D})}\left(\mathbf{E}^{\prime}(\boldsymbol{D}): \boldsymbol{\varepsilon}^{e}\right) \otimes\left(\mathbf{E}^{\prime}(\boldsymbol{D}): \boldsymbol{\varepsilon}^{e}\right)
$$

Eqn. (17) can easily describe the anisotropic damage behaviors of geomaterials in triaxial and uniaxial compressive tests.

\section{Plastic characterization}

The plastic strain rate is determined by the plastic yield function, the plastic hardening law, and the plastic flow rule in the case of non-viscous dissipation. An anisotropic plasticity framework is used due to the initial anisotropy of geomaterials. For most geomaterials, the non-linear unified strength criterion can be applied in order to produce the transition from plastic volumetric compressibility to dilatancy. The nonlinear unified strength theory has the following characteristics: (1) It is able to reflect the fundamental characteristics of rock, i.e., different tensile and compressive strengths, hydrostatic pressure effects, the effects of intermediate principal stress, zonal change, and material dependence. (2) It has a clear physics and mechanics background, a unified mathematical model, and simple and explicit criteria, which includes all independent stress components and simple material parameters. (3) It is also suitable for different types of rocks under various stress states, and it is consistent with other research regarding triaxial tests. The coupled elastoplastic damage models of geomaterials are 
different than those of metals. Generally, the plastic yield criterion and plastic potential can be conveyed by a scalar valued function that determines the thermodynamic force, stress tensor and damage variable, conjugated with an internal hardening variable.

Yield function can be written as follows:

$$
F^{p}\left(\boldsymbol{\sigma}, \boldsymbol{D}, \gamma_{p}\right) \leq 0
$$

Plastic potential function can be expressed as:

$$
Q\left(\sigma, \gamma_{p}\right) \leq 0
$$

The following modification of the three-dimensional nonlinear strength criterion proposed by Zhou et al. [34] is introduced to determine the damage of rock

$$
F^{p}(\sigma)=\sigma_{1}-\sigma_{3}-\sqrt{\left(n \sigma_{2}+m \sigma_{3}\right) \sigma_{c}+\sigma_{c}^{2}}
$$

where $n$ and $m$ are the strength parameters, $\sigma_{c}$ denotes uniaxial compressive strength of rocks, $\sigma_{1}, \sigma_{2}, \sigma_{3}$ are the major, intermediate and minor principal stresses, respectively.

When the damage variable is considered, the nonlinear strength criterion Eqn. (20) is rewritten in another form

$$
F^{p}\left(\sigma, \gamma_{p}, \boldsymbol{D}\right)=2 \sqrt{3 J_{2}} \cos \phi_{\sigma}-\sqrt{\sigma_{c}\left\{3 \sigma_{c}\left(1-\frac{\operatorname{tr} \boldsymbol{D}}{3}\right)+I_{1}(m+n)-\sqrt{J_{2}}\left[3 m \cos \phi_{\sigma}+\sqrt{3}(m-2 n) \sin \phi_{\sigma}\right]\right\}}=0
$$

where the stress angle is equal to $\phi_{\sigma}=\arctan \left[\frac{2 \sigma_{3}-\left(\sigma_{1}+\sigma_{2}\right)}{\sqrt{3}\left(\sigma_{1}+\sigma_{2}\right)}\right],-30^{\circ} \leq \phi_{\sigma} \leq 30^{\circ}, I_{1}$ is the first invariant of stress, $J_{2}$ is the second invariant of deviatoric stress tensor, $\sigma_{c}$ is an uniaxial compressive strength of an intact rock material, $m$ and $n$ are strength parameters of rocks.

The equivalent deviatoric plastic strain $\gamma_{p}$ is defined in terms of the Odquist parameter, which is traditionally used in $J_{2}$ plasticity to express plastic dissipation, in terms of von Mises stress and it includes the equivalent plastic strain rate:

$$
\dot{\gamma}_{p}=\sqrt{\frac{2}{3} \dot{\boldsymbol{e}}^{p}: \dot{\boldsymbol{e}}^{p}}
$$

where $\dot{e}^{p}$ denotes the rate of deviatoric plastic strain.

To ascertain the direction of the plastic strain rate, the following modification of the non-linear loading function is considered as a plastic potential function:

$$
Q\left(\sigma, \gamma_{p}\right)=4 J_{2} \cos ^{2} \phi_{\sigma}+\sigma_{c}\left[\cos \phi_{\sigma}+\frac{\sqrt{3}}{3}(m-2 n) \sin \phi_{\sigma}\right] \sqrt{J_{2}}-\frac{\beta \sigma_{c}}{3} I_{1}
$$

Here, the dilatation parameter $\beta$ is used to control inelastic volume expansion:

$$
\beta=\beta_{m}-\left(\beta_{m}-\beta_{0}\right) e^{-\eta_{3} \gamma_{p}}
$$

where the parameter $\eta_{3}$ denotes the exponential rule of the dilatation parameter $\beta$.

A non-associated plastic flow rule is utilized. The non-associated plastic flow rule and loading-unloading condition are described in the following: 


$$
\begin{aligned}
& \dot{\boldsymbol{\varepsilon}}^{p}=\dot{\lambda}_{p} \frac{\partial Q\left(\boldsymbol{\sigma}, \gamma_{p}\right)}{\partial \boldsymbol{\sigma}} \\
& F\left(\boldsymbol{\sigma}, \boldsymbol{D}, \gamma_{p}\right)=0, \quad \dot{\lambda}_{p} \geq 0, \quad F\left(\boldsymbol{\sigma}, \boldsymbol{D}, \gamma_{p}\right) \dot{\lambda}_{p}=0
\end{aligned}
$$

The change rate of the mean plastic strain $\varepsilon_{m}^{p}$ and deviatoric plastic strain $\boldsymbol{e}^{\boldsymbol{p}}$ is defined by:

$$
\left.\begin{array}{l}
\dot{\boldsymbol{\varepsilon}}_{m}^{p}=\dot{\lambda}_{p} \beta \\
\dot{\boldsymbol{e}}^{p}=\dot{\lambda}_{p} \frac{\boldsymbol{s}}{2 \sqrt{J_{2}}}
\end{array}\right\}
$$

From Eqn. (3), the plastic hardening function $\alpha_{p}\left(\gamma_{p}, \boldsymbol{D}\right)$ is concluded by a standard derivative of the thermodynamic potential [35]:

$$
\alpha_{p}\left(\gamma_{p}, \boldsymbol{D}\right)=\frac{\partial \psi\left(\varepsilon, \boldsymbol{D}, \gamma_{p}\right)}{\partial \gamma_{p}}=(1-\mu t r \boldsymbol{D})\left[\alpha_{p}^{m}-\alpha_{p}^{0}+2 B\left(\alpha_{p}^{m}-\alpha_{p}^{0}\right) \gamma_{p}\right]
$$

The scalar valued function $A\left(\gamma_{p}, \boldsymbol{D}\right)$ indicates the plastic hardening modulus, which is expressed as follows:

$$
A\left(\gamma_{p}, \boldsymbol{D}\right)=\frac{\partial F^{p}}{\partial \boldsymbol{\sigma}}: E(\boldsymbol{D}): \frac{\partial Q}{\partial \boldsymbol{\sigma}}-\frac{\partial F^{p}}{\partial \gamma_{p}}\left(\frac{\partial \gamma_{p}}{\partial \boldsymbol{\varepsilon}^{\boldsymbol{p}}}: \frac{\partial Q}{\partial \boldsymbol{\sigma}}\right)
$$

If $\dot{D}=0$, the plastic multiplier is resolved from the plastic consistency condition:

$$
\dot{\lambda}_{p}=\frac{\frac{\partial F^{p}}{\partial \boldsymbol{\sigma}}: \boldsymbol{E}(\boldsymbol{D}): \dot{\boldsymbol{\varepsilon}}}{A\left(\gamma_{p}, \boldsymbol{D}\right)+\frac{\partial F^{P}}{\partial \boldsymbol{\sigma}}: \boldsymbol{E}(\boldsymbol{D}): \frac{\partial Q}{\partial \boldsymbol{\sigma}}}
$$

The rate form of constitutive equations can be expressed as follows:

$$
\dot{\boldsymbol{\sigma}}=\boldsymbol{E}^{e p}: \dot{\boldsymbol{\varepsilon}}
$$

where $\boldsymbol{E}^{e p}$ is the fourth order tangent elastoplastic tensor given by:

$$
\boldsymbol{E}^{e p}(A, \boldsymbol{D})=\boldsymbol{E}(\boldsymbol{D})-\frac{\left(\boldsymbol{E}(\boldsymbol{D}): \frac{\partial Q}{\partial \boldsymbol{\sigma}}\right) \otimes\left(\boldsymbol{E}(\boldsymbol{D}): \frac{\partial F^{p}}{\partial \boldsymbol{\sigma}}\right)}{A\left(\gamma_{p}, \boldsymbol{D}\right)+\frac{\partial F^{p}}{\partial \boldsymbol{\sigma}}: \boldsymbol{E}(\boldsymbol{D}): \frac{\partial Q}{\partial \boldsymbol{\sigma}}}
$$

\section{Coupled elastoplastic damage behavior}

Under general loading conditions, plastic flow and damage evolution occur in a coupled process. Both the plastic strain and damage evolution rates should be determined concurrently, by applying the plastic and damage consistency conditions in a coupled system [36]. 


$$
\begin{aligned}
& \dot{F}^{P}\left(\boldsymbol{\sigma}, \boldsymbol{\varepsilon}_{p}, \boldsymbol{D}\right)=\frac{\partial F^{p}}{\partial \boldsymbol{\sigma}}: \dot{\boldsymbol{\sigma}}+\frac{\partial F^{p}}{\partial \gamma_{p}} \dot{\gamma}_{p}+\frac{\partial F^{p}}{\partial \boldsymbol{D}}: \dot{\boldsymbol{D}}=0 \\
& \dot{F}^{D}(\boldsymbol{Y}, \boldsymbol{D})=\frac{\partial F^{D}}{\partial \boldsymbol{Y}}: \dot{\boldsymbol{Y}}+\frac{\partial F^{D}}{\partial \boldsymbol{D}}: \dot{\boldsymbol{D}}=0
\end{aligned}
$$

By drawing the constitutive equations, the plastic hardening law, and damage criterion (33) (34), into one system, the plastic and damage multiplier can be determined [37-39]:

$$
\left\{\begin{array}{l}
\dot{\lambda}_{p}=\frac{R_{3} R_{4}-R_{1} R_{6}}{R_{2} R_{6}-R_{3} R_{5}} \\
\dot{\lambda}_{D}=\frac{R_{1} R_{5}-R_{2} R_{4}}{R_{2} R_{6}-R_{3} R_{5}}
\end{array}\right.
$$

where

$$
\begin{aligned}
& \mathrm{R}_{1}=\frac{\partial F^{p}}{\partial \boldsymbol{\sigma}}: \dot{\boldsymbol{\sigma}}, \mathrm{R}_{2}=\frac{\partial F^{p}}{\partial \gamma_{p}} \frac{\sqrt{s_{i j} s_{i j}}}{\sqrt{6 J_{2}}}, \mathrm{R}_{3}=\frac{\partial F^{p}}{\partial \boldsymbol{D}}:\left(\frac{\boldsymbol{Y}}{Y_{D}}\right), \mathrm{R}_{4}=-\frac{\boldsymbol{Y}}{Y_{D}}: \frac{\partial^{2} \psi}{\partial \boldsymbol{D} \partial \varepsilon^{e}}: \dot{\boldsymbol{\varepsilon}}^{e}, \mathrm{R}_{5}=-\frac{\boldsymbol{Y}}{Y_{D}}: \frac{\partial^{2} \psi}{\partial \boldsymbol{D} \partial \gamma_{p}} \frac{\sqrt{s_{i j} s_{i j}}}{\sqrt{6 J_{2}}}, \\
& \mathrm{R}_{6}=\left(\frac{\partial F^{D}}{\partial \boldsymbol{D}}-\frac{\boldsymbol{Y}}{Y_{D}}: \frac{\partial^{2} \psi}{\partial \boldsymbol{D} \partial \boldsymbol{D}}\right):\left(\frac{\boldsymbol{Y}}{Y_{D}}\right) .
\end{aligned}
$$

\section{NUMERICAL SIMULATIONS}

$\mathrm{F}$

or limestone, the below parameters are obtained in triaxial compression tests: $E_{0}=88.198 G P a, v_{0}=0.255$, $r_{\alpha}=0.004 m, k=1.5, \eta_{1}=133, \eta_{2}=1800, m=11.5, n=7.5, \mu=0.13, \beta_{0}=0.00012, \beta_{m}=0.00014, B=-0.25$, $\eta_{3}=1.33, Y_{0}=4.9795 \times 10^{5} \mathrm{~Pa}$. The dilute scheme, which is used for an elastic solid that has been weakened by an isotropic distribution of non-interacting closed microcracks[40-42], yields the following theoretical initial values of damage variable: $D_{11}=0.02, D_{22}=0.02$.

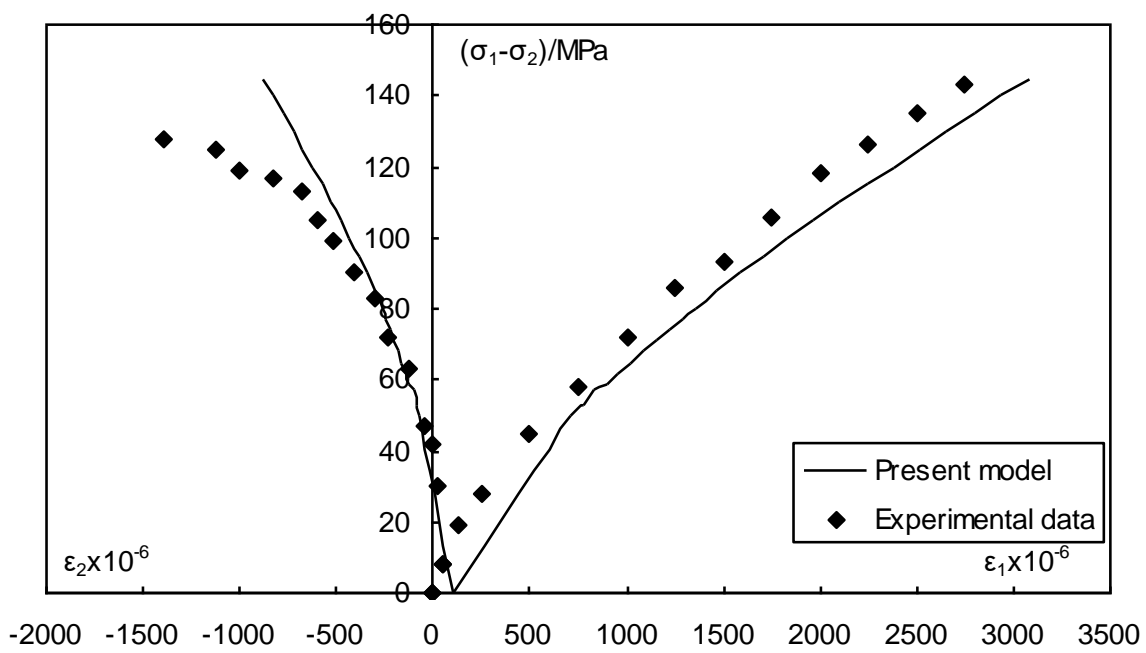

Figure 2: Simulation of stress-strain curve under triaxial compressive test with confining pressure $10 \mathrm{MPa}$ 


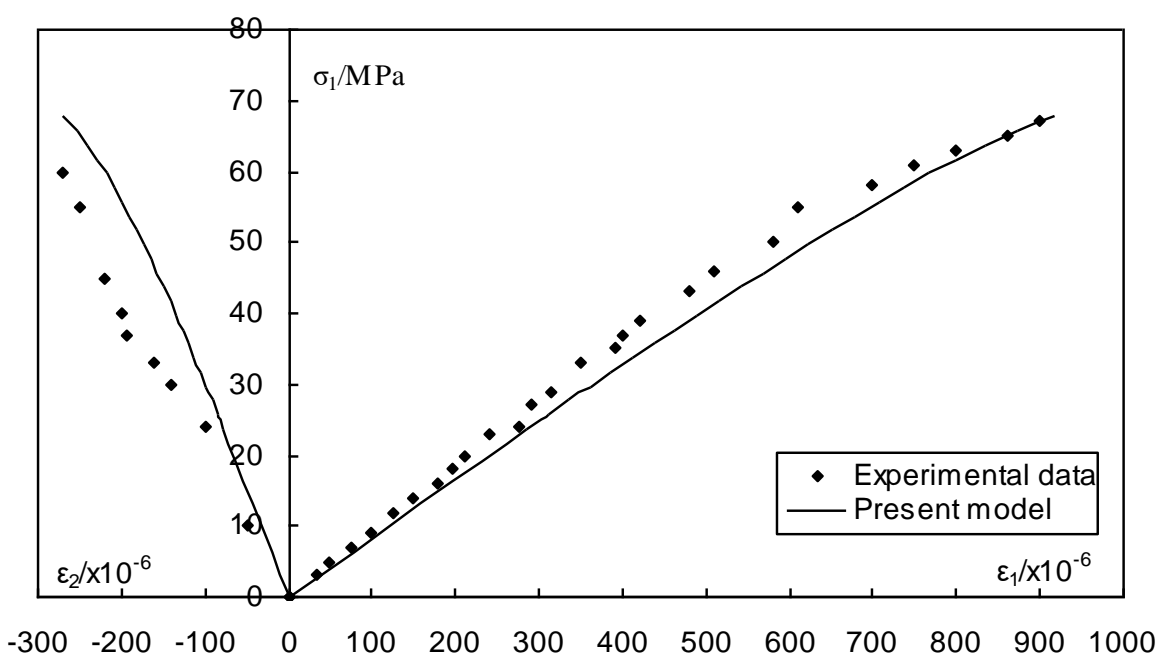

Figure 3: Simulation of stress-strain curve under uniaxial compressive test

Fig. 2 and Fig. 3 show comparisons between the experimental data for confining pressure at 10MPa and $0 \mathrm{MPa}$. A strong connection between the numerical simulations and experimental data was obtained. Since the triaxial tests have only determined the parameters of model, this comparison just verifies the consistency of the parameters.

\section{CONCLUSIONS}

$\mathrm{O}$ ur research proposes a new coupled elastoplastic damage model that addresses the coupled elastoplastic damage, found in the thermodynamics of semi-brittle geomaterials that have been subjected to compressive stresses. Our experiments applied the coupled elastoplastic damage model to a representative semi-brittle rock, namely limestone. The model can be used to describe anisotropic damage behaviors, elastoplastic deformation, pressure sensitivity, plastic compressibility and dilatancy, the degradation of elastic properties, and coupling between the plastic flow and damage of semi-brittle geomaterials, in triaxial and uniaxial compressive tests. The new model contains a small number of parameters, which can be obtained from standard triaxial compression tests. This study reveals a strong link between the numerical simulations and our experimental data, derived from our research with semi-brittle limestone that has been subjected to various loading paths.

\section{ACKNOWLEDGMENTS}

7 he work is supported by the National Natural Science Foundation of China (Nos. 41807251, 51809198 and 51839009), and the Fundamental Research Funds for the Central Universities (Grant No. 2042019kf0037).

\section{REFERENCES}

[1] Liu, X.S., Tan, Y.L., Ning, J.G., Lu, Y.W., Gu, Q.H. (2018). Mechanical properties and damage constitutive model of coal in coal-rock combined body, Int. J. Rock. Mech. Min. 110, pp.140-150. DOI: 10.1016/j.ijrmms.2018.07.020.

[2] Xie, H.P., Zhao, X.P., Liu, J.F., Zhang, R., Xue, D. (2012). Influence of different mining layouts on the mechanical properties of coal, Int. J. Min. Sci. Tech. 22(6), pp.749-755. DOI: 10.1016/j.ijmst.2012.12.010.

[3] Poulsen, B.A., Shen, B., Williams, D.J., Huddlestone-Holmes, C., Erarslanb, N., Qin, J. (2014). Strength reduction on saturation of coal and coal measures rocks with implications for coal pillar strength, Int. J. Rock. Mech. Min. 71, pp.4152. DOI: 10.1016/j.ijrmms.2014.06.012. 
[4] Bertuzzi, R., Douglas, K., Mostyn, G. (2016). An approach to model the strength of coal pillars, Int. J. Rock. Mech. Min. 89, pp.165-175. DOI: 10.1016/j.ijrmms.2016.09.003.

[5] Chen, D., Pan Z.J., Shi J.Q., Si, G., Ye, Z., Zhang, J. (2016). A novel approach for modelling coal permeability during transition from elastic to post-failure state using a modified logistic growth function, Int. J. Coal Geol. 163, pp. 132139. DOI: $10.1016 /$ j.coal.2016.07.007.

[6] Wu, C., Dou, L.M., Ju, Y., Cao, W., Yuan, S., Si, G. (2018). A plastic strain-based damage model for heterogeneous coal using cohesion and dilation angle, Int. J. Rock. Mech. Min.110, pp. 151-160. DOI: 10.1016/j.ijrmms.2018.08.001.

[7] Zhou, X.P., Zhang, Y.X., Ha, Q.L., Zhu, K.S. (2008). Micromechanical modelling of the complete stress-strain relationship for crack weakened rock subjected to compressive loading, Rock Mech. Rock Eng. 41(5), pp. 747-769. DOI: 10.1016/0020-7683(76)90044-5.

[8] Zhou, X.P., Li, G.Q., Ma, H.C. (2020). Real-time experiment investigations on the coupled thermomechanical and cracking behaviors in granite containing three pre-existing fissures, Eng. Fract. Mech. 224, 106797. DOI:10.1016/j.engfracmech.2019.106797.

[9] Zuo, J.P., Xie, H.P., Zhou, H.W. (2007). Thermal-mechanical coupled effect on fracture mechanism and plastic characteristics of sandstone, Sci. China Ser. E. 50, pp. 833-843. DOI: 10.1007/s11431-007-0081-6.

[10] Li, Y.W., Long, M., Zuo, L.H., Li, W., Zhao, W. (2019). Brittleness evaluation of coal based on statistical damage and energy evolution theory, J. Petrol Sci. Eng. 172, pp. 753-763. DOI: 10.1016/j.petrol.2018.08.069.

[11] Zhou, X.P. (2004). Analysis of the localization of deformation and the complete stress-strain relation for mesoscopic heterogeneous brittle rock under dynamic uniaxial tensile loading, Int. J. Solids Struct. 41 (5-6) , pp. 1725-1738.

DOI: $10.1016 /$ j.ijsolstr.2003.07.007.

[12] Zhou, X.P., Ha, Q.L., Zhang, Y.X., Zhu, K.S. (2004). Analysis of deformation localization and the complete stressstrain relation for brittle rock subjected to dynamic compressive loads, Int. J. Rock. Mech. Min. 41 (2) , pp. 311-319. DOI:10.1016/S1365-1609(03)00094-7.

[13] Shao, J. F., Lu, Y.F., Lydzba, D. (2004). Damage modeling of saturated rocks in drained and undrained conditions, J. Eng. Mech.-ASCE 130(6), pp. 733-740. DOI: 10.1061/(asce)0733-9399(2004)130:6(733).

[14] Ortiz,M. (1985). A constitutive theory for the inelastic behavior of concrete, Mech. Mater. 4, pp. 67-93. DOI: 10.1016/0167-6636(85)90007-9.

[15] Chow, C.L., June, W. (1987). An anisotropic theory of elasticity for continuum damage mechanics, Int. J. Fracture, 33, pp. 3-16. DOI: $10.1007 /$ bf00034895.

[16] Zhou, X.P., Yang, H.Q. (2007). Micromechanical modeling of dynamic compressive responses of mesoscopic heterogenous brittle rock, Theor. Appl. Fract. Mec. 48(1), pp. 1-20. DOI: 10.1016/j.tafmec.2007.04.008.

[17] Zhou, X.P. (2005). Triaxial compressive behavior of rock with mesoscopic heterogenous behavior: Strain energy density factor approach, Theor. Appl. Fract. Mec. 45(1), pp. 46-63, DOI: 10.1016/j.tafmec.2005.11.002.

[18] Zhou, X.P. (2005). Localization of deformation and stress-strain relation for mesoscopic heterogeneous brittle rock materials under unloading, Theor. Appl. Fract. Mec. 44(1), pp. 27-43. DOI: 10.1016/j.tafmec.2005.05.003.

[19] Shao, J.F., Jia, Y., Kondo, D., Chiarelli, A.S. (2006). A coupled elastoplastic damage model for semi-brittle materials and extension to unsaturated conditions, Mech. Mater. pp. 38(3), 218-232. DOI: 10.1016/j.mechmat.2005.07.002.

[20] Zhang, J.X., Wong, T.F., Davis, D.M. (1990). Micromechanics of pressured-induced grain crushing in porous rocks, J. Geophys Res.-Sol. Ea. 95, pp. 341-351. DOI: 10.1029/JB095iB01p00341.

[21] Budiansky, B., O’Connell, R.J. (1976). Elastic moduli of a cracked solid, Int. J. Solids Struct.12, pp. 81-97. DOI: 10.1016/0020-7683(76)90044-5.

[22] Yang, X.B., Xia, Y.J., Wang, X.J. (2012). Investigation into the nonlinear damage model of coal containing gas, Safety Sci. 50, pp. 927-930. DOI: 10.1016/j.ssci.2011.08.001.

[23] Horii, H., Nemat-Nasser, S. (1983). Overall moduli of solids with microcracks: load-induced anisotropy, J. Mech. Phys. Solids. 31, pp. 155-171. DOI: 10.1016/0022-5096(83)90048-0.

[24]Zhou, X.P., Wang, J.H. (2005). Study on the coalescence mechanism of splitting failure of crack-weakened rock subjected to compressive loads, Mech. Res. Commun. 32(2), pp. 161-171. DOI: 10.1016/j.mechrescom.2004.06.003.

[25] Hashin, Z. (1988). The differential scheme and its application to cracked materials, J. Mech. Phys. Solids, 36, 719-734. DOI: 10.1016/0022-5096(88)90005-1.

[26] Aboudi, J., Benveniste, Y. (1987). The effective moduli of cracked bodies in plane deformations, Eng. Fract. Mech. 26(2), pp. 171-184. DOI: 10.1016/0013-7944(87)90195-0.

[27] Zhou, X.P., Zhang, Y.X., Ha, Q.L., Zhu, K.S., (2004). Bounds on the complete stress-strain relation for a crackweakened rock mass under compressive loads, Int. J. Solids Struct. 41(22/23), pp. 6173-6196.

DOI: 10.1016/j.ijsolstr.2004.04.023. 
[28] Zhou, X.P. (2006). Upper and lower bounds for constitutive relation of crack-weakened rock masses under dynamic compressive loads, Theor. Appl. Fract. Mec. 46(1), pp. 75-86. DOI: 10.1016/j.tafmec.2006.05.004.

[29] Swoboda, G., Yang, Q. (1999). An energy-based damage model of geomaterials II: deduction of damage evolution laws, Int. J. Solids Struct. 36, pp. 1735-1755. DOI: 10.1016/S0020-7683(98)00164-4.

[30] Ostwald, R., Bartel, T., Menzel, A. (2015). An energy-barrier-based computational micro-sphere model for phasetransformations interacting with plasticity, Comput. Method Appl. M. 293, pp. 232-265.

DOI: $10.1016 /$ j.cma.2015.04.008.

[31] Abou-Chakra, Guéry, Cormery, F., Shao, J. F., Kondo, D. (2008). A micromechanical model of elastoplastic and damage behavior of a cohesive geomaterial, Int. J. Solids Struct. 45(5), pp. 1406-1429. DOI: 10.1016/j.ijsolstr.2007.09.025.

[32] Salar, M. R., Saeb, S., Willam, K. J., Patchet, J., Carrasco, R.C. (2004).A coupled elastoplastic damage model for geomaterials, Comput. Method Appl. M. 193(27-29), pp. 2625-2643. DOI: 10.1016/j.cma.2003.11.013.

[33] Welemane, H., Cormery, F. (2003). An alternative 3D model for damage induced anisotropy and unilateral effect in microcracked materials, J. Phys. IV France. 105, pp. 329-338. DOI: 10.1051/jp4:20030204.

[34] Zhou, X.P., Shou, Y.D., Qian, Q.H., Yu, M.H. (2014). Three-dimensional nonlinear strength criterion for rock-like materials based on the micromechanical method, Int. J. Rock. Mech. Min. 72, pp. 54-60.

DOI: $10.1016 /$ j.ijrmms.2014.08.013.

[35] Zheng, Q.S., Du, D.X. (2001). An explicit and universally applicable estimate for the effective properties of multiphase composites which account for inclusion distribution, J. Mech. Phys. Solids. 49, pp. 2765-2788.

DOI: 10.1016/s0022-5096(01)00078-3.

[36] Zhou, X.P., Li, X.H. (2009). Constitutive relationship of brittle rock subjected to dynamic uniaxial tensile loads with microcrack interaction effects, Theor. Appl. Fract. Mec. 52(3), pp. 140-145. DOI: 10.1016/j.tafmec.2009.09.002.

[37] Hashin, Z. (1988). The differential scheme and its application to cracked materials, J. Mech. Phys. Solids. 36, pp. 719734. DOI: 10.1016/0022-5096(88)90005-1.

[38] Aboudi, J., Benveniste, Y. (1987). The effective moduli of cracked bodies in plane deformations, Eng. Fract. Mech. 26(2), pp. 171-184. DOI: 10.1016/0013-7944(87)90195-0.

[39] Zhang, J.X., Wong, T.F., Davis, D.M. (1990). Micromechanics of pressured-induced grain crushing in porous rocks, J. Geophys Res.-Sol. Ea. 95, pp. 341-351. DOI: 10.1029/JB095iB01p00341.

[40] Zhou, X.P., Zhang, J.Z., Wong, L.N.Y., (2018). Experimental Study on the Growth, Coalescence and Wrapping Behaviors of 3D Cross-Embedded Flaws Under Uniaxial Compression, Rock Mech. Rock Eng. 51(5), pp. 1379-1400. DOI: 10.1007/s00603-018-1406-4.

[41] Zhou, X.P., Zhang, J.Z., Qian, Q.H., Niu, Y., (2019). Experimental investigation of progressive cracking processes in granite under uniaxial loading using digital imaging and AE techniques, J. Struct. Geol. 126, pp. 129-145.

DOI: $10.1016 /$ j.jsg.2019.06.003.

[42] Zhou, X.P., Lian, Y.J., Wong, L.N.Y., Berto, F. (2018). Understanding the fracture behavior of brittle and ductile multiflawed rocks by uniaxial loading by digital image correlation, Eng. Fract. Mech. 199, pp. 438-460.

DOI: 10.1016/j.engfracmech.2018.06.007. 